\title{
TU/e EN⿴HONE

\section{Nanostructuring of iron thin films by high flux low energy helium plasma}

\section{Citation for published version (APA):}

Bieberle-Hütter, A., Tanyeli, I., Lavrijsen, R., Koopmans, B., Sinha, R., \& van de Sanden, M. C. M. (2017). Nanostructuring of iron thin films by high flux low energy helium plasma. Thin Solid Films, 631, 50-56. https://doi.org/10.1016/j.tsf.2017.04.007

\section{Document license: \\ TAVERNE}

DOI:

10.1016/j.tsf.2017.04.007

Document status and date:

Published: 01/06/2017

\section{Document Version:}

Publisher's PDF, also known as Version of Record (includes final page, issue and volume numbers)

\section{Please check the document version of this publication:}

- A submitted manuscript is the version of the article upon submission and before peer-review. There can be important differences between the submitted version and the official published version of record. People interested in the research are advised to contact the author for the final version of the publication, or visit the $\mathrm{DOI}$ to the publisher's website.

- The final author version and the galley proof are versions of the publication after peer review.

- The final published version features the final layout of the paper including the volume, issue and page numbers.

Link to publication

\section{General rights}

Copyright and moral rights for the publications made accessible in the public portal are retained by the authors and/or other copyright owners and it is a condition of accessing publications that users recognise and abide by the legal requirements associated with these rights.

- Users may download and print one copy of any publication from the public portal for the purpose of private study or research.

- You may not further distribute the material or use it for any profit-making activity or commercial gain

- You may freely distribute the URL identifying the publication in the public portal.

If the publication is distributed under the terms of Article 25fa of the Dutch Copyright Act, indicated by the "Taverne" license above, please follow below link for the End User Agreement:

www.tue.nl/taverne

Take down policy

If you believe that this document breaches copyright please contact us at:

openaccess@tue.nl

providing details and we will investigate your claim. 


\title{
Nanostructuring of iron thin films by high flux low energy helium plasma
}

\author{
A. Bieberle-Hütter ${ }^{\text {a,* }}$, I. Tanyeli ${ }^{\text {a }}$, R. Lavrijsen ${ }^{\text {b }}$, B. Koopmans ${ }^{\text {b }}$, R. Sinha ${ }^{\text {a }}$, M.C.M. van de Sanden ${ }^{\text {a,c }}$ \\ a Electrochemical Materials and Interfaces, Dutch Institute for Fundamental Energy Research (DIFFER), Eindhoven, The Netherlands \\ ${ }^{\mathrm{b}}$ Physics of Nanostructures and center for NanoMaterials (cNM), Department of Applied Physics, Eindhoven University of Technology (TU/e), The Netherlands \\ c Plasma and Materials Processing, Department of Applied Physics, Eindhoven University of Technology (TU/e), The Netherlands
}

\section{A R T I C L E I N F O}

\section{Article history:}

Received 1 December 2016

Received in revised form 25 March 2017

Accepted 4 April 2017

Available online 05 April 2017

\section{Keywords:}

High ion flux plasma

Nanostructure

Iron thin film

Catalytic application

\begin{abstract}
A B S T R A C T
High flux, low energy He plasma exposure is proven to nanostructure iron thin films over their entire thickness to a highly open structure with large surface area. From a large set of plasma exposure parameters, the ion flux, the surface temperature, and the plasma exposure time are found to be the most relevant parameters to process mechanically stable, nanostructured Fe thin films on brittle glass substrates. The nanostructure stays stable during oxidation. Different surface morphologies are found, depending on the location where the plasma plume interacts with the thin film. This method paves the way to a new direction in top down nanostructuring of thin films, which can be adopted for many functional materials in diverse applications that require a high ratio of active to projected surface area.
\end{abstract}

C 2016 Published by Elsevier B.V.

\section{Introduction}

Catalytic and electrochemical reactions take place at the surface of materials. For many applications, such as sensors, fuel cells, electrolyser, water splitting cells, it is of paramount importance to create materials with large surface area and high amount of open porosity to enable more reactions to take place and increase performance. Thin films are often used in these applications due to the necessity for miniaturization and reduction of materials costs.

Thin films with large surface area are commonly produced by wet chemical deposition methods, such as spraying or sol gel processing [1], or through microfabrication [2]. Wet chemical deposited thin films often suffer from homogeneity issues, necessitating rather thick film thicknesses $(>100 \mathrm{~nm}$ ) to ensure continuous films with large surface area. Microfabrication is time and cost intensive. In addition, the fabricated nanostructures are mostly not percolating, but are shaped in nanowires, which is not always favored for functional applications due to connectivity reasons.

In the field of controlled fusion, the formation of nanofuzz on tungsten reactor wall components was recently described [3-10]. Nanofuzz in this context is the formation of highly structured, large surface area material formed on the walls of a fusion reactor due to high flux, low energy Helium (He) plasma exposure. Surfaces with $90 \%$ porosity were reported in [11] for plasma exposed tungsten. Such porous surfaces are attractive for catalytic and electrochemical applications. It was recently found that nanofuzz can be formed at bulk tungsten discs during high temperature, high flux, low energy He plasma exposure. After oxidation,

\footnotetext{
* Corresponding author.

E-mail address: a.bieberle@differ.nl (A. Bieberle-Hütter).
}

the evolved $\mathrm{WO}_{3}$ was used for water splitting [12]. A five times higher photocurrent of plasma exposed samples was found compared to non-exposed samples. Hence, it was proven that these plasma exposed surfaces do not only have a large surface area, but are also catalytically active. Kajita et al. also studied the morphology development during plasma exposure for possible water splitting application using Fe and Ta bulk pellets recently [13]. For water splitting and many other energy applications, however, thin films and not bulk material are used as electrodes due to costs, materials scarcity, and integration reasons. Hence, it is important to know whether high flux, low energy He plasma nanostructuring can be transferred to thin film surfaces and to structuring over the entire thickness of the thin film. The main challenges here are delamination of the thin film from the substrate, cracking of the substrate, chemical interdiffusion caused by the high temperatures used during the plasma treatment, and thermal gradients between the plasma exposed surface and the mounting.

In the literature, plasma treatment is reported for diverse purposes, such as cleaning of surfaces [14-16], activation of interfaces $[17,18]$, etching [19-21], and creation of oxygen vacancies [22]. Such plasma treatments are usually carried out with oxygen, hydrogen, or argon plasmas and use ion fluxes between $10^{18} \mathrm{~m}^{-2} \mathrm{~s}^{-1}$ to $10^{20} \mathrm{~m}^{-2} \mathrm{~s}^{-1}$. In this paper, we use a plasma with high ion flux of around $10^{23} \mathrm{~m}^{-2} \mathrm{~s}^{-1}[3-5,23]$ in order to fabricate nanostructures. The basic principle for nanostructuring with high ion flux plasma relies on $\mathrm{He}$ trapping into the material. Enrichment of the He in the structure leads to He bubbles which burst and lead to nanostructure formation [24].

We will prove in this paper that thin films can be nanostructured by high flux, low energy He plasma even on brittle and fragile substrates, such as glass. This will open up a new window for top down nanostructuring of thin films and the fabrication of large surface area 
films. The method can be adopted to many applications. In this paper, we will mainly focus on the nanostructuring of iron thin films on glass substrates as a proof of concept of nanostructuring of thin films and because it is a promising material to study the oxygen evolution reaction in water splitting devices due to its abundance, stability, and low costs [25-28].

\section{Experimental details}

\subsection{Thin film deposition}

All Fe thin films were deposited by DC magnetron sputtering from a $2 \mathrm{in}$., metallic target on glass substrates ( $1 \mathrm{~mm}$ thick) with a F: $\mathrm{SnO}_{2}$ (FTO) conducting layer. Substrates from manufacturers MTI (USA), Solems (F), and Solaronix $(\mathrm{CH})$ were used. A sputtering tool from Kurt J. Lesker was used with a base pressure $<10^{-8}$ mbar and a target-substrate distance of $95 \mathrm{~mm}$. All depositions were carried out at room temperature, at an Ar pressure of $1 \mathrm{~Pa}$, and a power of $100 \mathrm{~W}$. Different thicknesses were deposited with deposition times between $88 \mathrm{~s}$ and 881 s. Deposition times of $881 \mathrm{~s}$ resulted in a Fe film thickness of about $274 \mathrm{~nm}$ as shown by SEM in Fig. 1 and confirmed by atomic force microscopy step measurement.

\subsection{High flux, low energy He plasma exposure}

High flux low energy ( $20 \mathrm{eV}$ ) He plasma treatment was carried out in the Pilot PSI plasma set-up at DIFFER [23]. The magnetic field was $0.2 \mathrm{~T}$ and the bias voltage was set to $-20 \mathrm{~V}$. It was found in earlier studies that irradiating metals with ions having energy above the physical sputtering threshold resulted in considerable sputtering effect and, thus, reduction of thin film material during the plasma exposure [29, 30]. Source currents between $40 \mathrm{~A}$ and $100 \mathrm{~A}$ and He gas flow rates between $2.5 \mathrm{slm}$ and $4.8 \mathrm{slm}$ were used. This resulted in ion fluxes between $0.07 * 10^{22} \mathrm{~m}^{-2} \mathrm{~s}^{-1}$ and $1.4 * 10^{23} \mathrm{~m}^{-2} \mathrm{~s}^{-1}$ and surface temperatures between $150{ }^{\circ} \mathrm{C}$ and $780{ }^{\circ} \mathrm{C}$. The surface temperature was measured by infrared camera and pyrometer. The plasma exposure times were between $2 \mathrm{~min}$ and $50 \mathrm{~min}$.

\subsection{Annealing and characterization}

All Fe samples were annealed at $645{ }^{\circ} \mathrm{C}$ for $10 \mathrm{~min}$ in air with a ramping rate of $5{ }^{\circ} \mathrm{C} / \mathrm{min}$ in order to guarantee crystallization and oxidation of the Fe thin film while avoiding damage to the glass substrate. The morphologies of the thin films were characterized in top view and in cross section using a Field Emission Scanning Electron Microscope (SEM) (Zeiss Sigma, Germany). The porosity was estimated with the data analysis software Gwyddion [31].

\section{Results and discussion}

In order to find a suitable parameter space for plasma nanostructuring of thin films on glass substrates, the plasma exposure parameters were first varied on a large scale. It was found that source

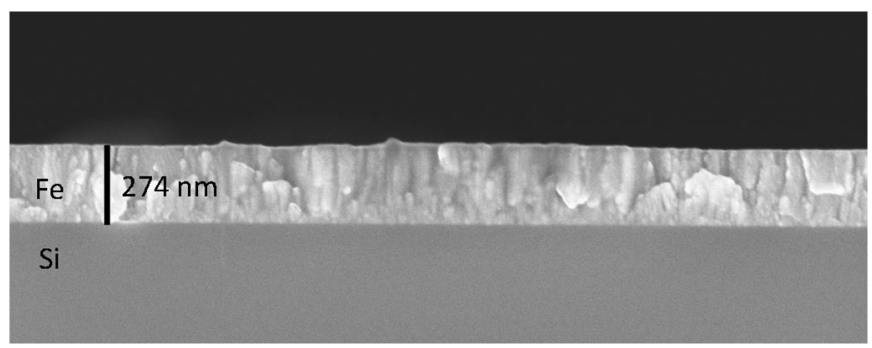

Fig. 1. Scanning electron microscopy image cross section of an as-deposited Fe thin film on Si (deposition time $881 \mathrm{~s}$ ). currents higher than 50 A resulted in sample breaking. This was related to local overheating of the substrate and consequent cracking due to the brittleness of the glass. At temperatures higher than $650^{\circ} \mathrm{C}$, glass substrates begin to soften and become rippled. Also, Sn diffusion from the FTO becomes relevant at higher temperature [32,33]. This means that much milder plasma conditions (lower temperature, lower source current) have to be chosen for plasma exposure of thin films on FTO-glass substrates compared to earlier high flux, low energy He plasma exposures of bulk materials [3-5].

In the following, we discuss Fe thin films on FTO-glass substrates and focus only on samples without mechanical damage, such as cracking or rippling. This means that we are restricting the plasma exposure parameters as discussed above. The plasma exposure parameters of these films are summarized in Table 1. It was found that all thin films adhere well to the substrate after plasma exposure. No delamination of the thin films from the substrates was detected.

\subsection{Optical imprint}

The as-deposited thin films are dark greyish and metallic shiny as typical for metallic thin films of several hundred nanometers on glass (Fig. 2a). After plasma exposure, the films are still metallic greyish and a circular mark - here termed optical imprint - is found that indicates where the surface was attacked by the plasma (Fig. 2b). A rough assessment of the impact of the plasma exposure on the thin films can be done by evaluating this optical imprint. It consists of concentric circles related to the Gaussian shape of the plasma plume over the exposed area. After annealing and oxidation at high temperature, the imprint becomes more clearly visible related to the color change from grey to orange. An example of a strong optical imprint (after high temperature oxidation and sample breaking for cross section characterization) is shown in Fig. 2c. The arrows and letters indicate locations that are later investigated in more detail.

The main parameters influencing the optical imprint were found to be the ion flux, the surface temperature, and the exposure time. Thin film thickness and the substrate manufacturer are not impacting the optical imprint. In general, three regions of optical imprint were identified and are illustrated together with all samples from Table 1 in Fig. 3: small optical imprint was found in the yellow region where two of the three main parameters are low. Medium imprint was found for samples where two of the plasma parameters were elevated, e.g. ion flux and temperature (ID 5) or temperature and exposure time (ID 8). The strongest optical imprint was observed in the red region with all three plasma exposure parameters being high, i.e. high ion flux, high temperature, and longest exposure time (ID 6).

\subsection{Microstructure}

In order to validate and quantify the observations of the optical imprints, top view SEM images were taken. Fig. 4 shows an as-deposited (Fig. 4a), an annealed (Fig. 4b), and several plasma exposed Fe thin films (Fig. 4c-f) for comparison; the images of the plasma exposed thin films were always taken in the middle of the imprint. The as-

Table 1

Summary of plasma exposed Fe thin films processed without mechanical damage.

\begin{tabular}{lllll}
\hline $\begin{array}{l}\text { Sample } \\
\text { ID }\end{array}$ & $\begin{array}{l}\text { Fe sputter } \\
\text { time }[\mathrm{s}]\end{array}$ & $\begin{array}{l}\text { Ion flux }\left[10^{23}\right. \\
\left.\mathrm{m}^{-1} \mathrm{~s}^{-1}\right]\end{array}$ & $\begin{array}{l}\text { Surface } \\
\text { temperature }\left[{ }^{\circ} \mathrm{C}\right]\end{array}$ & $\begin{array}{l}\text { Exposure time } \\
{[\mathrm{min}]}\end{array}$ \\
\hline 1 & 88 & 0.53 & 340 & 20 \\
2 & 88 & 0.53 & 500 & 20 \\
3 & 220 & 0.53 & 380 & 20 \\
4 & 220 & 0.53 & 550 & 20 \\
5 & 881 & 1.41 & 650 & 20 \\
6 & 881 & 1.06 & 650 & 50 \\
7 & 881 & 0.18 & 570 & 2 \\
8 & 881 & 0.071 & 650 & 40 \\
\hline
\end{tabular}


a)

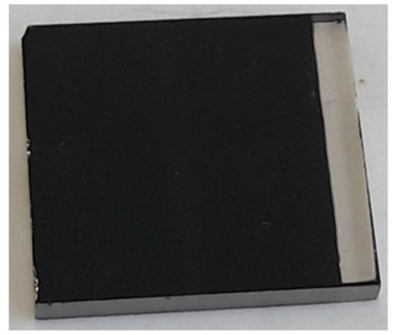

b)

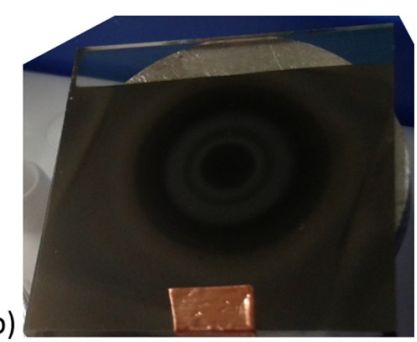

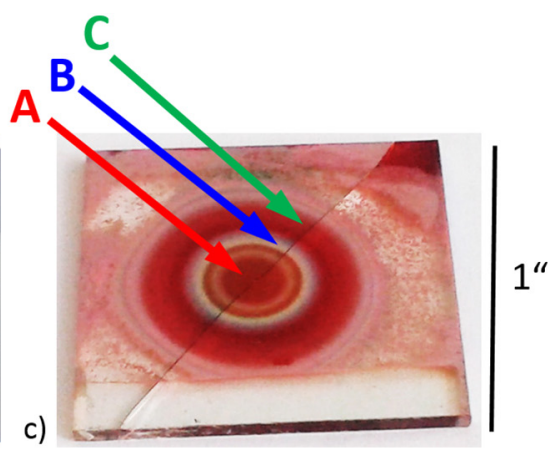

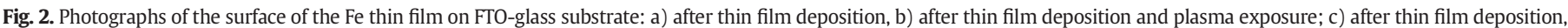

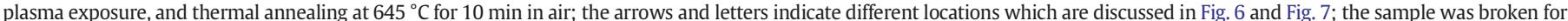
SEM cross section analysis.

deposited thin film (Fig. 4a) has a rough morphology with sharp grains of the order of $100 \mathrm{~nm}$. This structure is reproduced from the underlying FTO thin film. After annealing at $645^{\circ} \mathrm{C}$ for $10 \mathrm{~min}$ in air (Fig. 4b), nanowires of several hundred nanometer length developed (white, lengthy features) together with pores on the size of $30-50 \mathrm{~nm}$. Nanowire formation during high temperature oxidation of metal thin films is known in the literature [34-36]. The grains are between $30 \mathrm{~nm}$ and $100 \mathrm{~nm}$ in size.

The plasma exposed microstructures (before thermal oxidation) (Fig. 4c-f) look all very different and do not resemble the as-deposited thin film (Fig. 4a). Samples from the yellow region, i.e. low plasma parameters (Fig. 4c (ID 1) and Fig. 4d (ID 4)), are very smooth. The low temperature sample (Fig. 4c) has very small, non-distinct features of sizes smaller than $30 \mathrm{~nm}$. Individual holes are detected. The high temperature sample (Fig. $4 \mathrm{~d})$ has slightly larger feature sizes $(\sim 50 \mathrm{~nm})$, the features are less dispersed, and more distinct. More holes are visible and these holes are becoming connected. The morphologies of the samples in the yellow region (Fig. $4 \mathrm{c}$ and $\mathrm{d}$ ) are more similar to the unexposed thin film after annealing (Fig. 4b) than to the thin film before annealing (Fig. 4a); however, grain sizes are smaller and nanowires

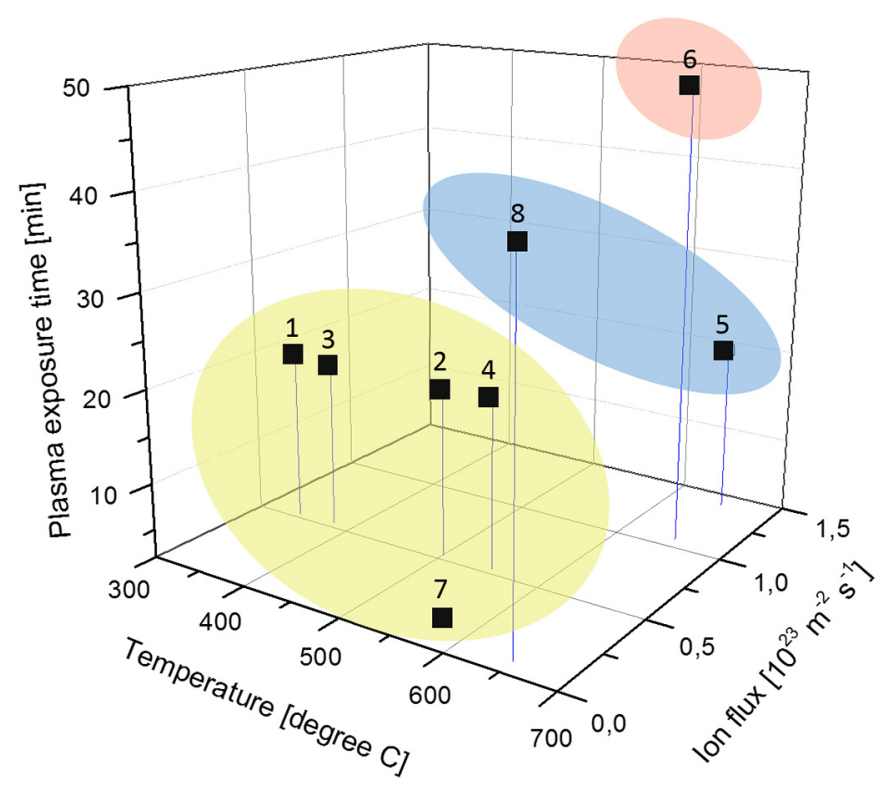

Fig. 3. 3D plot of the main plasma exposure parameters impacting the morphology of the thin films; three regions of with different impact of the plasma exposure are identified: yellow - small imprint, blue - medium imprint, red - strong imprint; the numbers correspond to the sample IDs in Table 1. (For interpretation of the references to colour in this figure legend, the reader is referred to the web version of this article.) are not present. This indicates that the plasma exposure in the yellow plasma exposure region has a similar effect as thermal annealing; holes appear, however, no nanostructure is formed. The thickness of the Fe thin film did not impact the morphology. The small holes can also be related to the first stage of nanostructure formation with reconstruction of the topmost surface as discussed in [24].

An example of the blue region where at least two plasma exposure parameters are high, is shown in Fig. 4e (ID 5). Large agglomerates of several hundred nanometers are found which are separated by relatively large pores. The small features on top of the large agglomerates are on the order of $20 \mathrm{~nm}$ to $50 \mathrm{~nm}$. The surface appears strongly attacked by the plasma treatment. Such surface reconstruction resembles the second stage of nanostructure formation with the formation of large He bubbles in the subsurface layer as discussed in Fig. 9c in reference [24].

The red region is the region where all plasma parameters are high: high ion flux of $>1 * 10^{23} \mathrm{~m}^{-2} \mathrm{~s}^{-1}$, high temperature of $650{ }^{\circ} \mathrm{C}$, and long exposure time of $50 \mathrm{~min}$. The surface has a very open structure with three-dimensionally connected features sized between $50 \mathrm{~nm}$ to $200 \mathrm{~nm}$. Analysis using the data analysis software Gwyddion resulted in a porosity of at least 70\% within the projected area. The morphology is comparable to the nanofuzz found in bulk materials after plasma exposure [3-5,13,24].

In summary, the three different regions as defined from optical imprint were confirmed by SEM analysis. In the yellow region, the plasma exposure parameters are soft and all three characteristic parameters are low or medium. No nanostructure formation is found. In the blue region, the plasma exposure parameters are medium meaning that two of the characteristic parameters are high at the same time, e.g. ion flux and temperature or temperature and exposure time. Although the microstructure is strongly attacked by the plasma treatment, no nanostructure formation is observed. In the red region, all characteristic parameters are high and a nanostructured surface is formed.

\subsection{Oxidation and high temperature stability}

The plasma-exposed Fe thin films were annealed in air at $645^{\circ} \mathrm{C}$ for $10 \mathrm{~min}$ in order to oxidize the films. The oxidation is accompanied by a change in color: while the as-deposited, metallic Fe thin films are darkgreyish, the oxidized iron films are orange, illustrated in Fig. 2a to $c$ and pointing towards the formation of hematite $\left(\mathrm{Fe}_{2} \mathrm{O}_{3}\right)$. Detailed x-ray diffraction and $\mathrm{x}$-ray photoelectron spectroscopy studies confirmed this and will be published elsewhere together with the functional characterization of these plasma nanostructured thin films for water splitting application. Metal oxide thin films are required in many applications and it is of high interest to see whether the nanostructure is stable during high temperature annealing and oxidation and whether plasma exposure impacts the microstructure during annealing. Fig. 5 shows examples of thin film surfaces after plasma exposure and subsequent annealing in air at $645^{\circ} \mathrm{C}$ for 10 min for one sample from the yellow region (ID 1 , 
a)

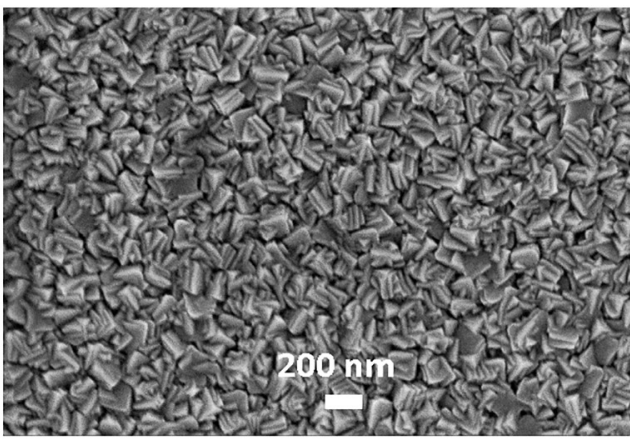

c)

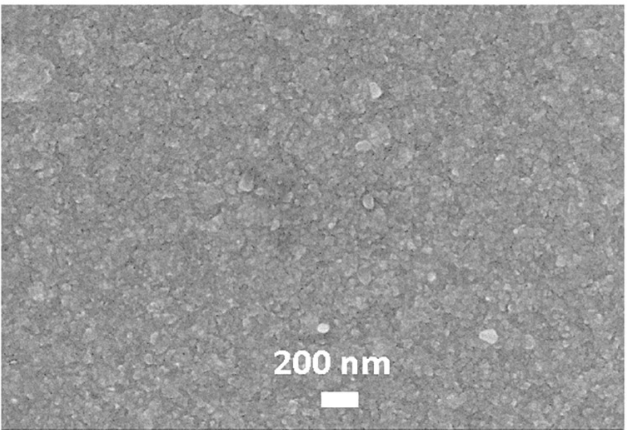

e)

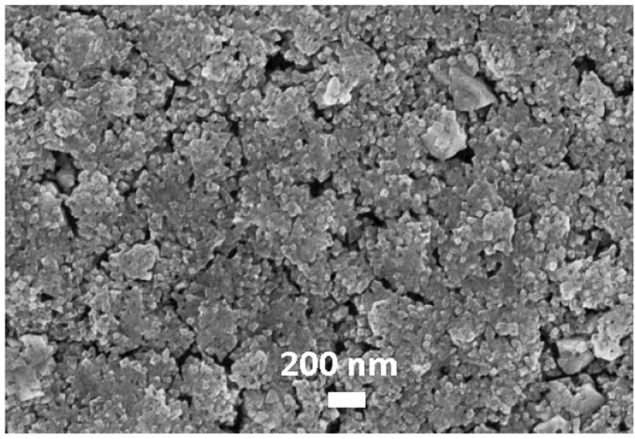

b)

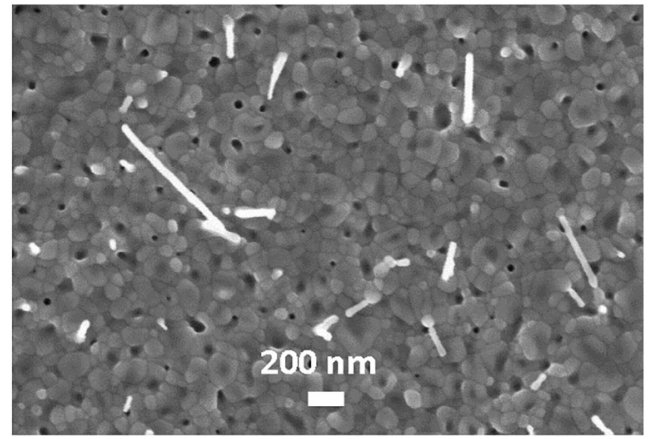

d)
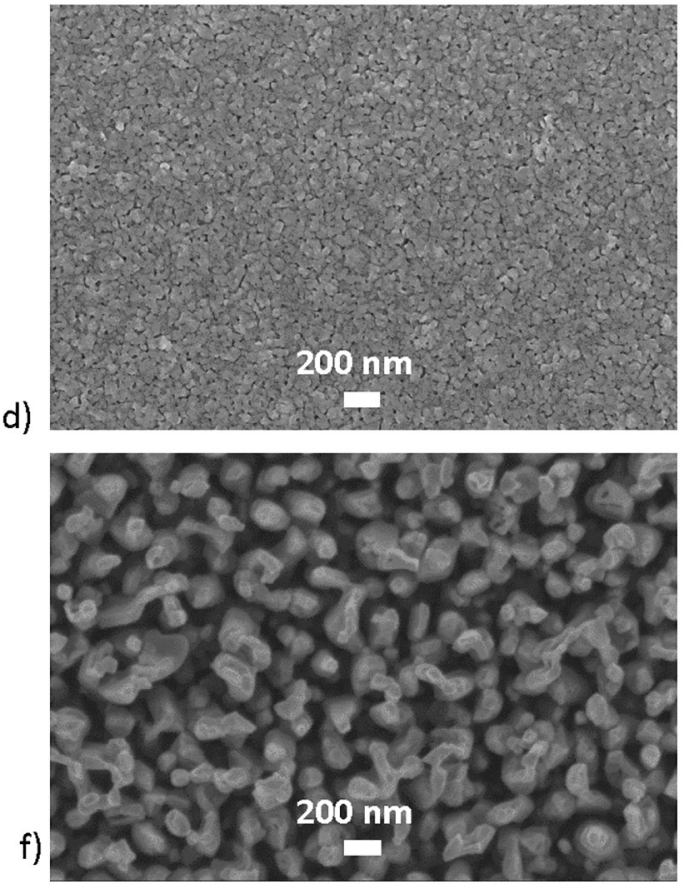

Fig. 4. Top view SEM images of Fe thin films a) after thin film deposition, b) after annealing at $645^{\circ} \mathrm{C}$ for $10 \mathrm{~min}$ in air,c)-f) after plasma exposure: c) thin film from yellow region after low temperature plasma exposure (ID 1), d) thin film from yellow region after high temperature plasma exposure (ID 4), e) thin film from blue region (ID 5), f) thin film from red region (ID 6). The sample IDs and colors of the regions correspond to the labelling in Table 1 and Fig. 3, respectively.

Fig. 5a) and one samples from the red region (ID 6, Fig. 5b). The morphology of the low temperature exposed sample shows distinct grains and more holes after annealing (Fig. 5a) compared to the image before annealing (Fig. 4c). The structure resembles more the annealed plain film (Fig. 4b), but without nanowire formation. Nanowire formation is hindered during the plasma treatment due to the He bombardment and the low oxygen partial pressure. Hence, the temperature during the plasma process might simply have resulted in the formation of the holes and the changes in the morphology and the plasma treatment itself did not change the morphology.

The nanostructured surface after plasma exposure (Fig. 4f) and after subsequent high temperature oxidation (Fig. 5b) are very similar. This means that the nanostructure is stable during oxidation and that no coarsening of the nanostructure is observed during annealing.

\subsection{Spatial distribution of the nanostructure formation}

The high flux, low energy He plasma plume in the Pilot-PSI set-up is known to have a Gaussian shape over the projected area. This results in an optical imprint consisting of concentric rings. The microstructure was analyzed at different locations in these concentric rings. Fig. $2 \mathrm{c}$ indicates the locations where the microstructure was analyzed in the highly nanostructured sample (ID 6, Table 1); the corresponding top view SEM images are shown in Fig. 6 before and after annealing in air. A highly nanostructured surface is found in the middle of the imprint (location A). At location B, a distinct, granular structure with feature sizes of $100 \mathrm{~nm}$ to $200 \mathrm{~nm}$ and rectangularly shaped grains are found. Close to the edge of the imprint (location $\mathrm{C}$ ), the features have similar size as the features in location $\mathrm{B}$, however, the shape has become rounded. This indicates that the distance between the individual features has increased and that a more open structure has developed. The microstructure is stable during annealing in all locations. No coarsening of the features is observed.

The corresponding cross section SEM images are shown in Fig. 7. In the center of the sample (location A, Fig. 6), the best nanostructure is found in the top view analysis. The cross section confirms the nanostructure formation (Fig. 7a). The nanostructuring was found through the entire thickness of the thin film down to the FTO. The structure is thee-dimensionally connected. Location B (Fig. 7b) is characteristic for a dense microstructure without nanostructure; this is comparable with the top view images in Fig. 6. The plasma parameters are milder in this location and do not lead to nanostructure formation. Surface reconstruction and bubble formation such as described in [24] for bulk material are visible. Location C (Fig. 7c) is partly dense and has large openings in between the single grains. These can be related to He bubble formation as described in [24]. 
a

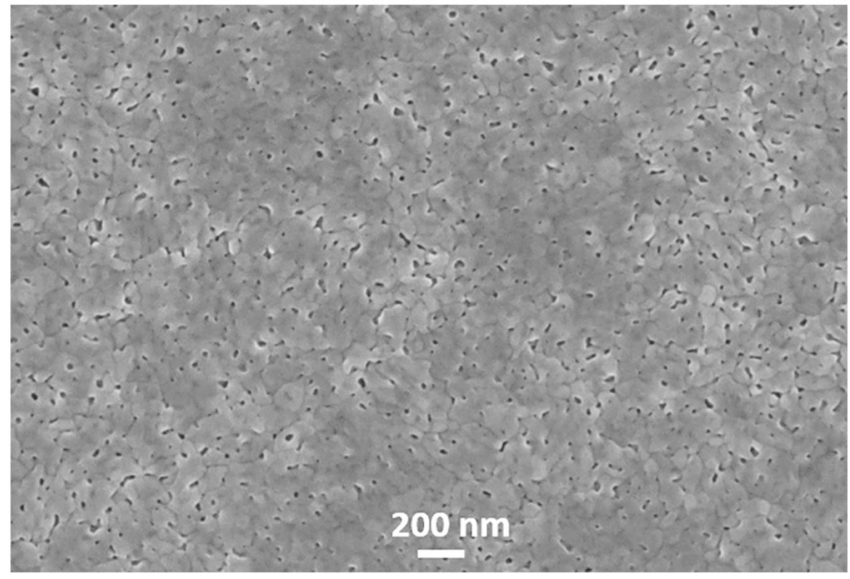

b

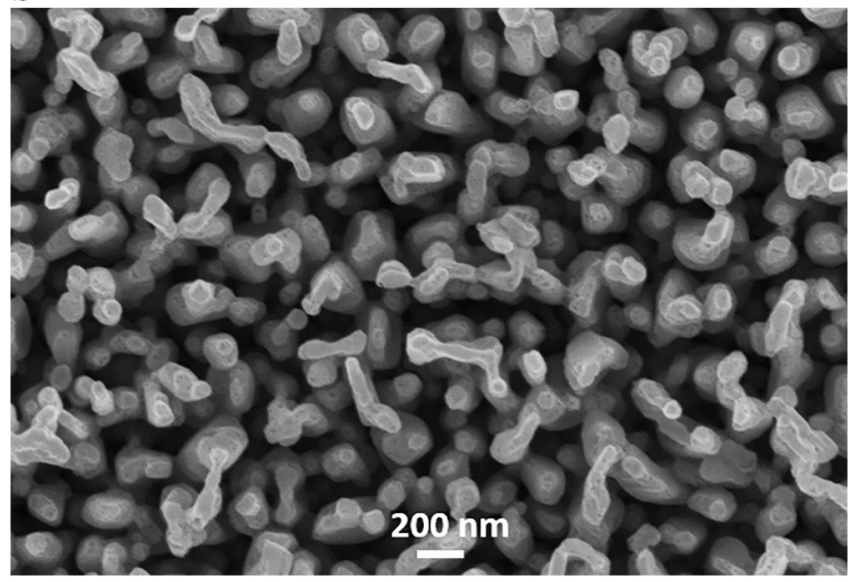

Fig. 5. Top view SEM images of Fe thin films after plasma exposure and annealing at $645^{\circ} \mathrm{C}$ for 10 min in air: a) thin film from yellow region (ID 1), b) thin film from red region (ID 6 ). The sample IDs and colors of the regions correspond to the labelling in Table 1 and Fig. 3, respectively.

The film thicknesses of the iron oxide thin film and the FTO are marked with the same length of white and yellow bars, respectively, in Fig. 7. For all three cross section, the thin film was about $689 \mathrm{~nm}$ thick after oxidation. From the as-deposited thickness of $274 \mathrm{~nm}$, an oxidized film thickness of $588 \mathrm{~nm}$ was expected; hence, the thin films after plasma exposure are slightly thicker than expected. This is attributed to the material reorganization during plasma exposure and the formation of pores [24]. The fact that the highly nanostructured part of the thin film (Fig. 7a) is not thicker than at the other locations points towards a slight erosion of material during the plasma exposure process in this region of the sample.

Assuming the same FTO thickness in all three locations of the sample, slight damage of the FTO in the highly nanostructured region cannot be excluded because of a slightly thinner FTO thickness in location A; note that the yellow line is not completely positioned where the FTO layer seems to end. For all locations, the interface between the iron oxide layer and the FTO is intimate and no delamination between the FTO-glass substrate and the oxidized thin film is detected at any of the three locations. This confirms the strong adhesion of the thin films to the substrate also after plasma exposure which is an important characteristic for thin films used in applications.

\section{Summary}

In summary, high flux, low energy He plasma exposure was shown to successfully nanostructure Fe thin films. It was proven that even brittle substrates, such as glass, can be used in this process. The nanostructures are three-dimensionally connected, stable during oxidation, and adhere well to the substrate. The nanostructure formation is mainly determined by the ion flux, the surface temperature, and the exposure time. The mechanism of nanostructure formation was found to be comparable to that of bulk material as reported in the literature. High flux, low energy He plasma exposure was introduced as a new path for nanostructuring of thin films. This technique can be adopted in many applications in the fields of energy generation, storage and sensing. It has to be proven to which extent the thin film and nanostructure properties scale with the surface area and the porosity.

\section{Acknowledgements}

Bieberle-Hütter, Sinha and Van de Sanden acknowledge the financial support from NWO (program nr. 147 “ $\mathrm{CO}_{2}$ neutral fuels”). The research of Tanyeli was supported by the European Communities under the contract of Association between EURATOM and FOM (grant nr. 633053) and was conducted within the framework of the European Fusion Program. The authors thank the Nanolab at TU Eindhoven for access to SEM.
A
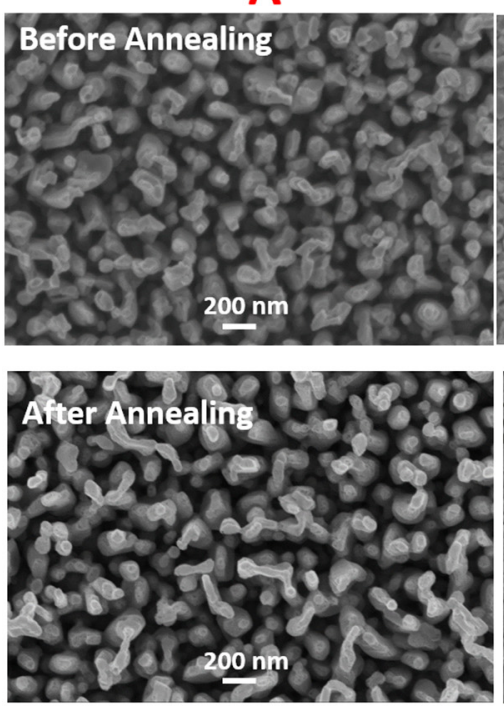

B
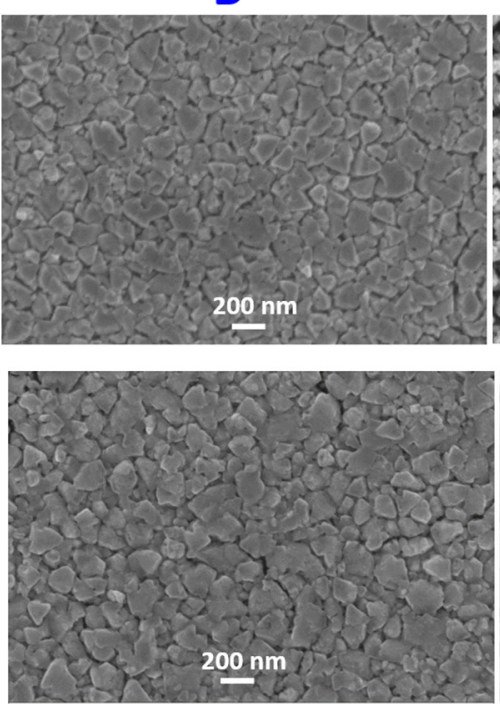

C
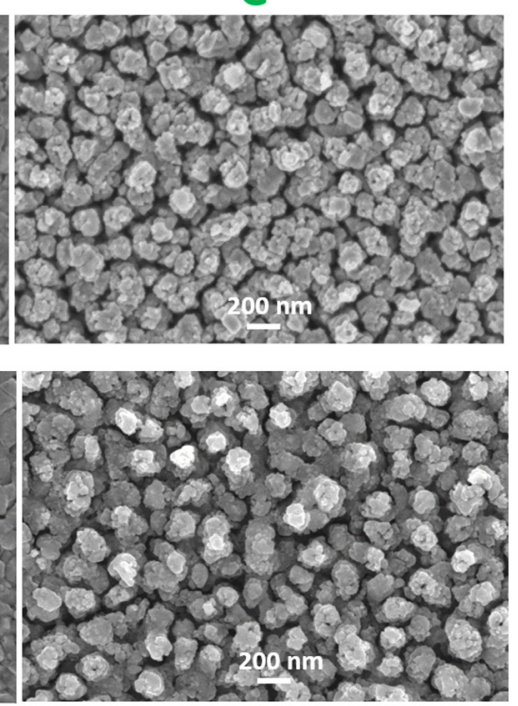

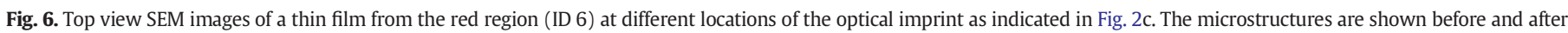
annealing at $\mathrm{T}_{\max }=645^{\circ} \mathrm{C}, \mathrm{t}=10 \mathrm{~min}$, in air, using a heating rate of $5^{\circ} \mathrm{C} / \mathrm{min}$. 
a)
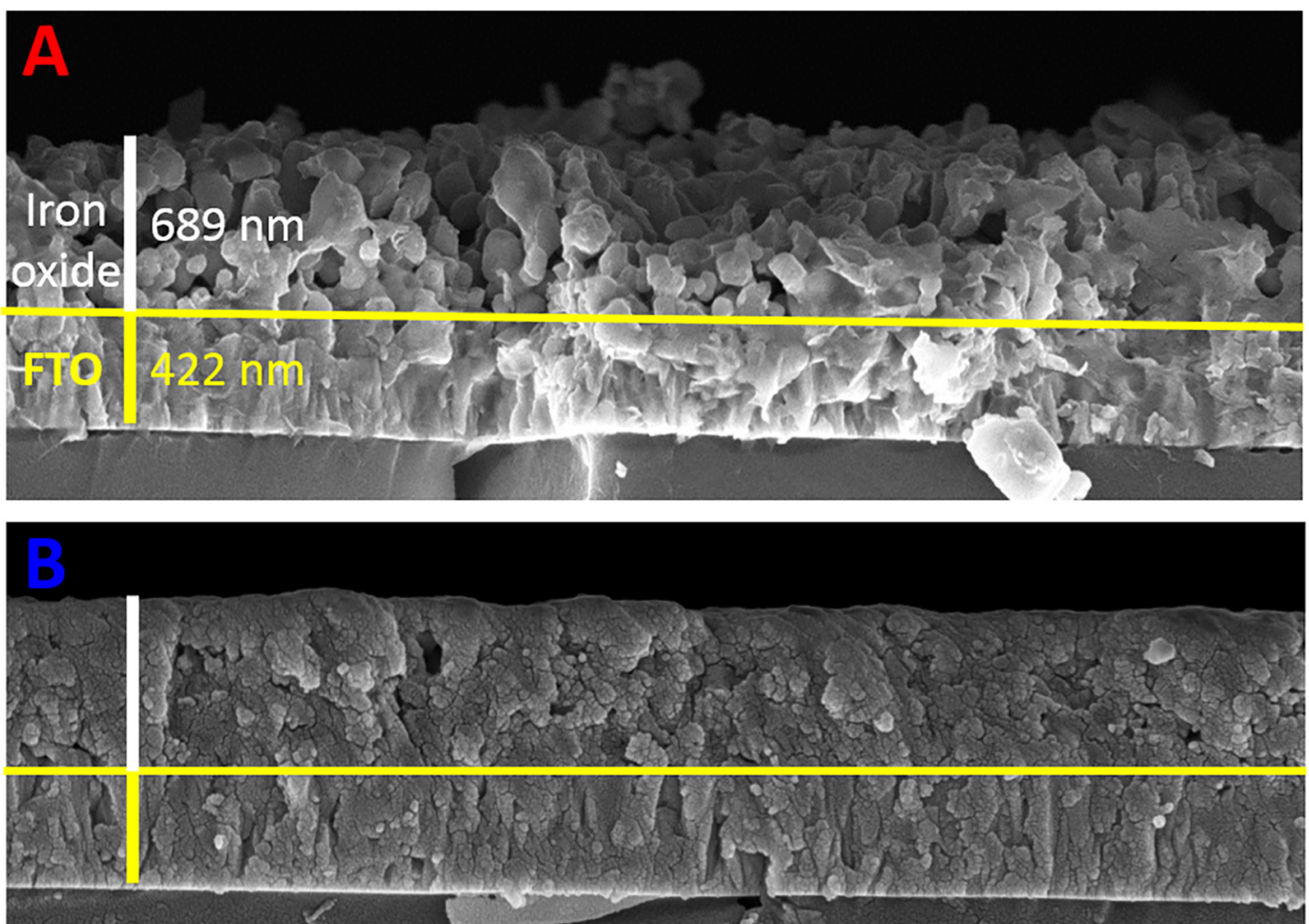

b)
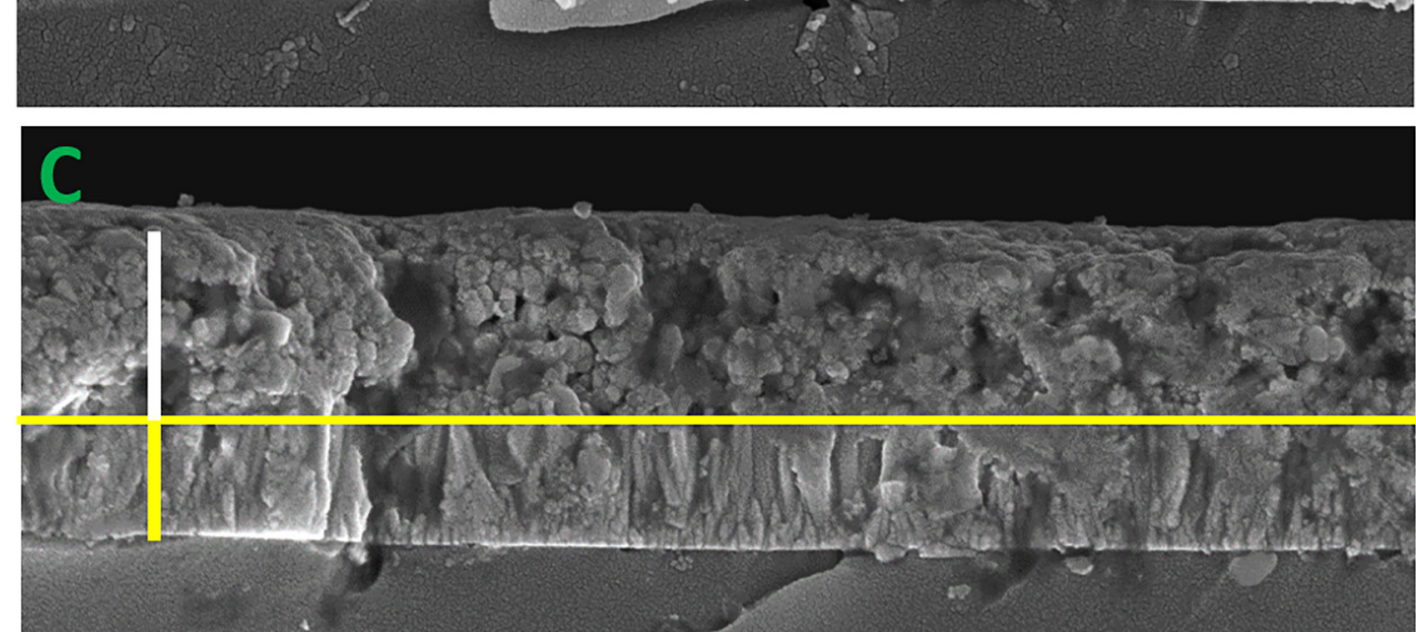

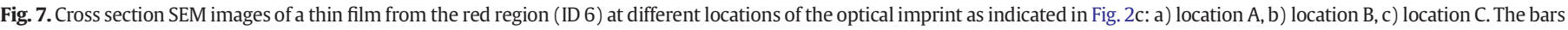
indicating the thickness of the iron oxide and FTO thin films, respectively, are all of the same length and illustrate that thin film thicknesses are similar at all locations.

\section{References}

[1] D. Beckel, A. Bieberle-Hütter, A. Harvey, A. Infortuna, U.P. Muecke, M. Prestat, J.L.M. Rupp, L.J. Gauckler, Thin films for micro solid oxide fuel cells, J. Power Sources 173 (2007) 325-345.

[2] M.J. Madou, Fundamentals of Microfabrication: The Science of Miniaturization, CRC Press, Boca Raton, Florida, 2002

[3] G. De Temmerman, K. Bystrov, J.J. Zielinski, M. Balden, G. Matern, C. Arnas, L. Marot, Nanostructuring of molybdenum and tungsten surfaces by low-energy helium ions, J. Vac. Sci. Technol. A 30 (2012) 041306.

[4] I. Tanyeli, L. Marot, M.C.M. van de Sanden, G. De Temmerman, Nanostructuring of iron surfaces by low-energy helium ions, ACS Appl. Mater. Interfaces 6 (2014) 3462-3468.

[5] I. Tanyeli, L. Marot, D. Mathys, M.C.M. van de Sanden, G. De Temmerman, Surface modifications induced by high fluxes of low energy helium ions, Sci. Rep. 5 (2015) 9779.

[6] S. Takamura, N. Ohno, D.D. Nishijima, S. Kajita, Formation of nanostructured tungsten with arborescent shape due to helium plasma irradiation, J. Plasma Fusion Res. 1 (2006) 51.

[7] M.J. Baldwin, R.P. Doerner, Formation of helium induced nanostructure 'fuzz' on various tungsten grades, J. Nucl. Mater. 404 (2010) 165-173.

[8] M.J. Baldwin, R.P. Doerner, Helium induced nanoscopic morphology on tungsten under fusion relevant plasma conditions, Nucl. Fusion 2008 (2008) 035001-035005.
[9] G.M. Wright, D. Brunner, M.J. Baldwin, R.P. Doerner, B. Labombard, B. Lipschultz, J.L. Terry, D.G. Whyte, Tungsten nano-tendril growth in the Alcator C-Mod divertor, Nucl. Fusion 52 (2012) 042003-042008.

[10] S. Takamura, T. Miyamoto, N. Ohno, Effects of fibre-form nanostructures on particle emissions from a tungsten surface in plasmas, Nucl. Fusion 52 (2012) 123001-123008.

[11] S. Kajita, T. Saeki, N. Yoshida, N. Ohno, A. Iwamae, Nanostructured black metal: novel fabrication method by use of self-growing helium bubbles, Appl. Phys. Express 3 (2010) $085204085201-085203$.

[12] M. De Respinis, G. De Temmerman, I. Tanyeli, M.C.M. van de Sanden, R.P. Doerner, M.J. Baldwin, R. van de Krol, Efficient plasma route to nanostructure materials: case study on the use of $\mathrm{m}-\mathrm{WO}_{3}$ for solar water splitting, ACS Appl. Mater. Interfaces 5 (2013) 7621-7625.

[13] S. Kajita, T. Ishida, N. Ohno, D. Hwangbo, T. Yoshida, Fuzzy nanostructure growth on Ta/Fe by He plasma irradiation, Sci. Rep. 6 (2016) 30380 30381-30310.

[14] B.-O. Aronsson, J. Lausmaa, B. Kasemo, Glow discharge plasma treatment for surface cleaning and modification of metallic biomaterials, J. Biomed. Mater. Res. 35 (1997) 49-73.

[15] W. Kern, The evolution of silicon wafer cleaning technology, J. Electrochem. Soc. 137 (1990) 1887-1892.

[16] S.C. Lim, S.H. Kim, J.H. Lee, M.K. Kim, D.J. Kim, T. Zyung, Surface-treatment effects on organic thin-film transistors, Synth. Met. 148 (2005) 75-79.

[17] P. Amirfeiz, S. Bengtsson, M. Bergh, E. Zanghellini, L. Börjesson, Formation of silicon structures by plasma-activated wafer bonding, J. Electrochem. Soc. 147 (2000) 2693-2698. 
[18] T. Suni, K. Henttinen, I. Suni, J. Mäkinen, Effects of plasma activation on hydrophilic bonding of $\mathrm{Si}$ and $\mathrm{SiO}_{2}$, J. Electrochem. Soc. 149 (2002) G348-G351.

[19] D.M. Manos, D.L. Flamm, Plasma Etching - An Introduction, Academic Press, Inc., San Diego, USA, 1989.

[20] J.W. Coburn, H.F. Winters, Plasma etching-a discussion of mechanisms, J. Vac. Sci. Technol. 16 (1979) 391-403.

[21] M. Haass, M. Darnon, G. Cunge, O. Joubert, D. Gahan, Silicon etching in a pulsed HBr/ $\mathrm{O}_{2}$ plasma. I. Ion flux and energy analysis, J. Vac. Sci. Technol. B 33 (2015) 032202 032201-032208.

[22] C. Zhu, C. Li, M. Zheng, J.-J. Delaunay, Plasma induced oxygen vacancies in ultrathin hematite nanoflakes promoting PEC water oxidation, ACS Appl. Mater. Interfaces 7 (2015) 22355-22363.

[23] G. De Temmerman, J.J. Zielinski, S. Van Diepen, L. Marot, M. Price, ELM simulation experiments on Pilot-PSI using simultaneous high flux plasma and transient heat/ particle source, Nucl. Fusion 51 (2011) 073008-073008-073008.

[24] S. Kajita, N. Yoshida, R. Yoshihara, N. Ohno, M.J. Yamagiwa, TEM observation of the growth process of helium nanobubbles on tungsten: nanostructure formation mechanism, Nucl. Mater. 418 (2011) 152-158.

[25] K. Sivula, F. Le Formal, M. Grätzel, Solar water splitting: progress using hematite ( $\alpha$ $\mathrm{Fe}_{2} \mathrm{O}_{3}$ ) photoelectrodes, ChemSusChem 4 (2011) 432-449.

[26] J.Y. Kim, G. Magesh, D.H. Youn, J.W. Jang, J. Kubota, K. Domen, J.S. Lee, Single-crystalline, wormlike hematite photoanodes for efficient solar water splitting, Sci. Rep. 3 (2013) 2681.
[27] Y. Ling, G. Wang, H. Wang, Y. Yang, Y. Li, Low-temperature activation of hematite nanowires for photoelectrochemical water oxidation, ChemSusChem 7 (2014) $848-853$.

[28] T. Hisatomi, H. Dotan, M. Stefik, K. Sivula, A. Rothschild, M. Grätzel, N. Mathews, Enhancement in the performance of ultrathin hematite photoanode for water splitting by an oxide underlayer, Adv. Energy Mater. 24 (2012) 2699-2702.

[29] D. Nishijima, M.J. Baldwin, R.P. Doerner, J.H. Yu, Sputtering properties of tungsten 'fuzzy' surfaces, J. Nucl. Mater. 415 (2011) S96-S99.

[30] W. Eckstein, Calculated Sputtering, Reflection and Range Values, Report of the MaxPlanck-Institute für Plasmaphysik (IPP-Report 9/132), Garching, Germany, 2002.

[31] http://gwyddion.net/ last accessed October 18, 2016.

[32] R.G. Gordon, Criteria for choosing transparent conductors, MRS Bull. 25 (2000) 52-57.

[33] K. Goto, T. Kawashima, N. Tanabe, Heat-resisting TCO films for PV cells, Sol. Energy Mater. Sol. Cells 90 (2006) 3251-3260.

[34] D.A. Voss, E.P. Butler, T.E. Mitchell, The growth of hematite blades during the high temperature oxidation of iron, Metall. Trans. A. 13A (1982) 929-935.

[35] L. Yuan, Y. Wang, R. Cai, Q. Jiang, J. Wang, B. Li, A. Sharmae, G. Zhoua, The origin of hematite nanowire growth during the thermal oxidation of iron, Mater. Sci. Eng. B 177 (2012) 327-336.

[36] Y.Y. Fu, R.M. Wang, J. Xu, J. Chen, Y. Yan, A.V. Narlikar, H. Zhang, Synthesis of large arrays of aligned a- $\mathrm{Fe}_{2} \mathrm{O}_{3}$ nanowires, Chem. Phys. Lett. 379 (2003) 373-379. 